\title{
CLOUD BASED E-GOVERNMENT MODEL: ANALYSIS AND CHALLENGES
}

\author{
Neha Paliwal \\ Research Scholar, Department of Computer Science \& Engineering, \\ Suresh Gyan Vihar University, Jaipur, India \\ Dr. Bright Keswani \\ Professor, Department of Computer Science \& Engineering, \\ Suresh Gyan Vihar University, Jaipur, India \\ Vani Jain \\ Research Scholar, Department of Computer Science \& Engineering, \\ Suresh Gyan Vihar University, Jaipur, India

\section{Dr. Devesh Bandil} \\ Associate Professor, Department of Computer Science \& Engineering, \\ Suresh Gyan Vihar University, Jaipur, India
}

\begin{abstract}
There is growing proof that the Cloud Computing offerings have turn out to be a strategic path for governments' IT paintings with the aid of using the sunrise of the third-millennium. The inevitability of this computing generation has been diagnosed now no longer best with inside the advanced nations just like the UK, USA and Japan, however additionally with inside the growing nations just like the Middle East location and Malaysia, who've released migrations closer to Cloud systems for extra flexible, open, and collaborative public offerings. In India, the cloud-primarily based totally eauthorities task has been deemed as one of the excessive precedence regions for the authorities businesses. In spite of its extra special evolution, numerous governmental cloud- primarily based totally offerings nevertheless going through adoption demanding situations of e-authorities initiatives like technological, human-factors, social, and economic which want to be handled and taken into consideration cautiously with the aid of using any authorities business enterprise taking into account its implementation. While there had been good sized efforts to analyze the e-authorities adoption from the residents' angle the use of exceptional theories and fashions, none have paid good enough interest to the safety troubles. This paper explores the exceptional views of the volume wherein those demanding situations inhibit the reputation and use of cloud computing in Indian public region. In addition to inspecting the impact of those demanding situations at the contributors' protection notion.
\end{abstract}


The empirical proof supplied a complete of 220 legitimate responses to our on line questionnaire from Indian residents consisting of IT- workforce from exceptional authorities sectors. Based at the statistics evaluation a few full-size demanding situations had been diagnosed. The consequences can assist the coverage makers with inside the public region to manual a success reputation and adoption of cloud-primarily based totally e-authorities offerings in India.

Key words: Cloud Computing, Cloud systems, e- authorities, IT- workforce, E-Government.

Cite this Article: Neha Paliwal, Bright Keswani, Vani Jain and Devesh Bandil, Cloud based E-Government Model: Analysis and Challenges, International Journal of Management (IJM), 11(12), 2020, pp. 3202-3223.

http://iaeme.com/Home/issue/IJM?Volume=11\&Issue=12

\section{INTRODUCTION}

Development of Information and Communication Technology (ICT) is one of the full-size traits of our generation and, like different innovations, it has an essential affect in phrases of converting and modernization human beings existence to a few volume. Specifically, the evolution of ICT has a dramatic extrude in residents' interplay with their governments, extensively growing their expectancies on this regard $[1,2]$. With the inception of e-authorities structures, some of authorities agencies international have moved far from the conventional shape of public administrations to digital forms, as they found out the significance of handing over first-rate and extra green offerings to its residents [3, 4]. However, the in addition usage of e-authorities offerings ended in extra adoption and reputation demanding situations like technological and economic ones [4, 5]. Innovative ICT, along with cloud computing generation can make contributions to triumph over those demanding situations; cloud computing represents a essential extrude with inside the technological surroundings production of the general public region and the manner that governments behavior their commercial enterprise $[6,7]$. In the beyond decades, the governmental region targeted predominantly at the conventional on line net- primarily based totally offerings to decorate accountability, transparency, and accessibility to public offerings and facts. Led with the aid of using the pioneering projects in lots of advanced nations along with UK, Japan, USA and EU [8,9], cloud generation made a success development closer to being the subsequent-technology of eauthority's offerings. The concept is to make use of ubiquitous, particularly scalable, locationimpartial IT sources to increase organizational techniques and reinvent the authorities offerings that meet residents' expectancies to enhance collaboration among authorities businesses with extra flexible, open, low- fee and unified computing. However, the cloud- primarily based totally e-authorities taken into consideration as a profound extrude inside governments additionally represents a person- centric offerings platform aiming to growth residents' participation. In current years, the general public region with inside the growing nations, in particular, the Middle East have commenced gearing closer to cloud computing to gain an expanded stage of performance and overall performance whilst presenting fee-powerful outcome [10]. However, some of those governments are nevertheless with inside the preliminary ranges of that manner. The states of India , the with inside the coronary heart of Middle East location, is with inside the manner of entire migration to Cloud-Government. India realized the critical position of the Cloud Computing with inside the e-authorities context and released the primary "National Cloud Platform", designed to gain persistent upgrades and increase in the e- authorities programs [11]. In those days, some of authorities entities and ministries follow cloud-primarily based totally answers to offer progressed public offerings to their residents; however, a excessive-percent of Indian nationals do now no longer but use 
cloud-primarily based totally e- authorities offerings and nevertheless, depend upon paper printouts in their respectable transactions. Accordingly, the offerings supplied primarily based totally at the cloud computing generation just like the "Issuing Certificate of Non- Criminal Record" aren't exploited efficiently. A quantity of theories and fashions of IS/IT reputation, like Theory of Planned Behavior (TPB), Technology Acceptance Model (TAM) and, the modern advanced version, the second one model of the Unified Theory of Acceptance and Use of Technology (UTAUT2), had been in large part carried out to observe the people' reluctance or low adoption of recent e-authorities offerings [12]. However, those theoretical fashions, consisting of the UTAUT2 itself, are criticized for now no longer thinking about the constructs depicting the particular views of e- authorities (e.g. protection). This paper takes a step closer to answering the query: "Do the boundaries and demanding situations of e-authorities adoption affect using cloud-primarily based totally e-authorities offerings from the Indian residents' and authorities' angle?". The findings of this studies demonstrated that a few e-authorities demanding situations nevertheless affect the reputation of cloud-primarily based totally public offerings just like the lack of expertise and protection. In addition to validating a number of the safety issues associated with this studies context, subsequently those may be considered while formulating a brand new theoretical version.

\section{CHALLENGES OF E-GOVERNMENT}

E-authorities projects intention to elevate the extent of governments' overall performance whilst imparting the residents with upgraded public offerings. However, some of authors imply that exceptional sorts of boundaries are confronted with the aid of using authorities entities which hindered the attaining of e-authorities promised dreams and degraded its a success adoption [8, 13]. Therefore, the general public region has the duty to triumph over such hard hurdles. Despite the governments' efforts on this regard, the achievement of e- authorities projects is contingent upon residents' willingness to apply and be given the e-authorities offerings using new ICT [3]. Notably, Security is one of the full-size reasons of hesitation approximately e- authorities offerings because of lingering perceived protection issues [14]. The maximum encountered demanding situations of e- authorities reputation and adoption may be grouped into classes as mentioned in Table 1.

\subsection{Technological Challenges}

The e-authorities projects deployment become for a long term limited with the aid of using technological troubles. For instance, loss of protection is a essential impediment in enforcing e-authorities offerings in step with residents' issues [15]. This phase illustrates the primary boundaries face e-authorities from the technical thing.

\subsection{IT Infrastructure}

Although the taking place of IT fee, enough IT infrastructure continues to be taken into consideration as one of the maximum not unusual place boundaries to e-authorities offerings, additionally affect citizen adoption of such offerings [16, 17]. It composed of networks along with LAN (nearby place community), WAN community (Extranet, Intranet and Internet), different technical components, databases and running structures. Creating new verbal exchange channels to supply and percentage the e-authorities facts and offerings calls for good enough internetworking [17, 18]. Similarly, Ebrahim and Irani (2005) asserted the importance of internetworking potential as a base for IS integration throughout the general public region. Also, IT infrastructure might be skilled with the aid of using loss of software program and hardware. In many growing nations, the bad IT infrastructure frequently prohibits the a success 
implementation of e-authorities. Consequently, governments require helping a robust IT infrastructure to allow the residents to gain from e- authorities offerings.

\subsection{Security}

Security refers back to the safety of structures, facts, and statistics in opposition to intentional or unintended disclosure, copying and alteration because of unauthorized get right of entry to [19]. A quantity of research have diagnosed protection as a full-size barrier affect the goal to apply the e- authorities offerings throughout the world, and this is from each governments' and residents' angle [15-17]. While there may be a consensus some of the studies network that protection could have technical or non-technical factors, the non-technical troubles have extra affect with inside the growing nations. The Perceived facts protection may be described as "the subjective opportunity with which customers trust that their private facts will now no longer be considered, saved or manipulated at some point of transit or garage with the aid of using beside the point parties, in a way steady with their assured expectancies" [20]. So, perceived protection is an critical detail to construct the accept as true with among the authorities and its residents. As said with the aid of using Ndou (2004), governments around the world want to stable the transactions among the authorities agencies and people. 21.three.

\subsection{Availability}

The improvement any Information System IS like e-authorities may want to bring about many demanding situations to the inner and outside stakeholders (e.g. availability and accessibility) $[17,21,22]$. It is critical to differentiate among those terminologies. Availability refers back to the quantity of e-offerings which are to be had for the residents 24/7 [17]. As illustrated with the aid of using Criado et al. (2003), the critical guarantees of e- authority's initiatives may be completed with the aid of using an integration of numerous elements, for example, accessibility and availability [23]. Moreover, availability improves residents' pleasure with of e- authority's machine because of its pivotal affect at the provider quality [24]. By contrast, the shortage of those essential elements might result in failure of e-authorities efforts. While the above-stated dialogue factors out the supply as a rating trendy for the achievement and adoption of eauthorities, accessibility to e- authority's offerings is likewise important.

\subsection{Accessibility}

Accessibility time period is used to explain the approaches wherein residents' achieve on line authority's offerings and facts thru of a couple of e-channels [16, 22]. The presence of such channels makes the provider on hand to all sorts of residents in spite of religion, house vicinity or maybe disabilities. Alomari et al. (2012) proposed the provider accessibility as an essential predictor to set up "citizen-centric" e- authorities offerings. Thus, the authorities businesses ought to make certain the accessibility and availability in their net offerings to all stakeholders from exceptional places across the clock. For example, governments may want to release loose Wi-Fi provider inside a country wide approach to inspire the residents' participation in eauthorities offerings.

\subsection{Website Layout}

Recently, the governments' web sites have emerged as the primary gateways for handing over public offerings to residents $[22,25]$. Research on e- authorities has located that web site design is a full-size aspect affected citizen's willingness to just accept e-authorities offerings [22]. Standardized layout and well-prepared content material growth the customers' goal to apply eauthorities. In addition, express protection rules, instructions, and password suggestions ought 
to be ensured with inside the layout of internet site; due that residents' use of e-authorities is a questionable rely with out a protection assure [26].

\subsection{Human Aspects}

"Once the human beings have the infrastructure to head on line, they want the focus, competencies and on line content material to inspire their get right of entry to" [27] The research indicates that loss of each focus and IT-competencies are the 2 dominant human-factors below the boundaries to e-authorities projects [18].

\subsection{Lack of Focus}

In preferred, residents have restrained focus approximately e-authorities offerings and its advantages [28]. It has been located that the lack of expertise is one of the barriers to a success adoption of E-authorities [25, 29]. Awareness refers back to the person's expertise of others' sports, which yields to a context for his personal sports [25]. Lack of focus is a foundation for low charges of residents' participation and failure of e-authorities initiatives [24]. Therefore, governments ought to provoke appealing focus campaigns to sell new e- authorities offerings and to gain its a success diffusion and implementation.

\subsection{ICT Competencies}

Two sorts of competencies are required to apply e- authorities structures with the aid of using residents. These are: IT literacy and Information protection literacy. The dearth of those competencies is a important project to e-authorities projects, specifically in growing nations [30]. IT-Literacy used to signify the marginalized those who are incapable to apply ICT because of the shortage of pc information and training [17]. While the facts protection literacy approach the shortage of simple information approximately the stable on line practices [31]. In fact, the governments had to offer their residents with the critical pc, protection and net competencies to enhance their participation in e- authorities. In this regard, Almarabeh and AbuAli (2010) emphasized the critical significance of residents' training, because it prevents the upward push of companies in the society "facts bad" and "facts rich".

\subsection{Social Challenges}

Social troubles to the adoption of e-authorities aren't a technological barrier, however as a substitute hinge on social implications of recent IT. The social thing consists of some of demanding situations like income, language, tradition, training and virtual divide. In recognize to this observe, tradition might be clarified.

\subsection{Culture}

The powerful implementation and adoption of e- Government offerings want to triumph over the cultural demanding situations $[22,32]$. Culture may be diagnosed with the aid of using various factors along with human beings values, ideals, behaviour and religion. Also, normally it could be categorized into 3 types: organisational tradition, country wide tradition, and protection tradition. In the context of this observe, It is essential to make clear precisely what is supposed with the aid of using "protection tradition" which refers back to the socio-behaviour and customs of a particular society, that have an effect on their protection practices [33]. Resistance to extrude with the aid of using residents can also additionally lead ultimately to poor effects concerning e- authorities participation [32]. Therefore, it is required from the governments to enhance the social existence and set up a information-primarily based totally society so that you can extrude IT-tradition in their residents. 


\subsection{Financial Challenges}

Even if the general public region has the powerful techniques to put in force the e-authorities and to triumph over the aforementioned demanding situations; it could be argued that isn't sufficient to make certain the a success projects of e-authorities. This is attributable to the excessive fee of the protection and implementation of the IT structures, which ended in a investment predicament of e-authorities projects [34]. Thus, some of authors have asserted the "loss of economic recourses" as a outstanding project of e-authorities [8, 28, 29], specifically with inside the growing nations. Also, to keep away from the investment barrier, public perceived usefulness Human-factors Lack of lack of expertise approximately e- [24, 25, awareness government services and its benefits 28] loss of orientation campaigns to sell eauthorities ICT competencies Lack of IT competencies amongst customers of e-authorities (i.e. residents, personnel, IT workforce) Lack of baseline information associated with the stable on line practices $[25,31]$ Social Culture Religious and tribal ideals Language issues Change resistance [32, 35] Financial Lack of finances / excessive fee High maintenance and operational fee High finances for protection answers $[15,16]$ While a good deal of the preceding literature has targeted at the e-authorities demanding situations from exceptional views (i.e. authorities stakeholders), pretty little has been carried out to observe the effect of those demanding situations at the adoption and reputation of cloud-primarily based totally offerings with inside the public administrations want to assure long-duration economic help for the e-authorities as it's miles a long- time period initiative.

Table 1 Categories of E-Government Adoption Challenges

\begin{tabular}{|c|c|c|}
\hline Issues & Examples & Ref. \\
\hline \multicolumn{3}{|l|}{ Technological } \\
\hline - IT infrastructure & $\begin{array}{l}\text { - inadequate networking capability } \\
\text { - insufficient integration of systems } \\
\text { - unsuccessfully maintained hardware and software } \\
\text { - inappropriateness andintricacy of the existing systems }\end{array}$ & {$[16,30]$} \\
\hline - Security & $\begin{array}{l}\text { short of transactions' protection } \\
\text { - absence of trust in online and government e-services } \\
\text { - absence of security hardware in the public sector }\end{array}$ & $\begin{array}{l}{[15-17,} \\
25,30]\end{array}$ \\
\hline - Availability & $\begin{array}{l}\text { - lack of ability to deliver services and information on request } \\
\text { - delayed response to citizens expectations, making } \\
\text { ineffective delivery of the e-services. }\end{array}$ & {$[24,30]$} \\
\hline - Accessibility & $\begin{array}{l}\text { - complexity to access the system by the people with } \\
\text { disabilities } \\
\text { - Internet coverage is partial }\end{array}$ & {$[30,32]$} \\
\hline \multirow[t]{2}{*}{ - Website design } & - restricted languages to present & {$[22,24$,} \\
\hline & $\begin{array}{l}\text { the website content } \\
\text { - perceived ease of use }\end{array}$ & 25] \\
\hline \multicolumn{3}{|l|}{ Human-factors } \\
\hline $\begin{array}{l}\text { - Short of } \\
\text { awareness }\end{array}$ & $\begin{array}{l}\text { short of knowledge about e- government services and its } \\
\text { benefits } \\
\text { - Short of orientation campaigns to encourage e-government }\end{array}$ & $\begin{array}{l}{[24,25} \\
28]\end{array}$ \\
\hline
\end{tabular}




\begin{tabular}{|l|l|l|}
\hline - ICT skills & $\begin{array}{l}\text { - short of IT skills amongst users of e-government (i.e. } \\
\text { citizens, employees, IT staff) } \\
\text { - short of baseline knowledge associated to the secure online } \\
\text { practices }\end{array}$ & {$[\mathbf{2 5 , 3 1 ]}$} \\
\hline Social & $\begin{array}{l}\text { - Religious and tribal beliefs } \\
\text { - Language problems } \\
\text { - Change resistance }\end{array}$ & {$[\mathbf{3 2 , 3 5 ]}$} \\
\hline Financial & $\begin{array}{l}\text { - High maintenance andoperational cost } \\
\text { - High budget for security solutions }\end{array}$ & {$[\mathbf{1 5 , 1 6}]$} \\
\hline
\end{tabular}

Examples Ref. Technological IT infrastructure In sufficient networking potential Inadequate integration throughout structures Poorly updated hardware and software program incompatibility and complexity of the present structures $[16,30]$ Security lack of transactions' [15-17, protection lack of trust in online and 25,30] authorities e-offerings loss of protection hardware with inside the public region Availability Inability to supply offerings and facts upon request Slow reaction to residents expectancies ,making unsuccessful transport of the eofferings. [24, 30] Accessibility Difficulty to get right of entry to the machine with the aid of using the human beings with disabilities Internet insurance is restrained [30, 32] Website layout restrained languages to gift $[22,24$, the website content perceived ease of use 25] region context. Furthermore, the volume to which those demanding situations are pertinent to the perceived protection of cloud-primarily based totally e-authorities offerings. Consequently, there may be a concurrent want to benefit an empirical exam for the affect of such demanding situations at the reputation and protection of cloud computing offerings and programs with inside the public region. In this paper, an internet survey become carried out to gain this observe intention.

\section{CLOUD COMPUTING}

Cloud Computing has turn out to be a full-size milestone with inside the improvement of Information Systems (IS) and a salient IT approach for governments, due presenting particularly-scalable computing sources. According to the definition supplied with the aid of using National Institute of Standards and Technology (NIST), Cloud computing is " a version for allowing ubiquitous, handy, on-call for community get right of entry to a shared pool of configurable computing sources that may be swiftly provisioned and launched with minimum control attempt or provider issuer interplay" [36]. Cloud Computing is taken into consideration as one of the maximum promising ITs nowadays, inherently has awesome traits consist of huge community get right of entry to, on- call for self-provider, speedy elasticity, pooled sources, measured provider (Fig 1) [36]. Wang et al. (2016) use the time period 'cloud computing' to seek advice from "the transport of computing as a provider instead of a product" [37]. This provider is supplied to the authorities businesses, commercial enterprise, and people on 3 exceptional fashions consisting of Infrastructure as a Service (IaaS), Platform as Service (PaaS), and Software as Service (SaaS). Also, primarily based totally at the scope of utilization, cloud computing may be grouped into 4 deployment fashions, which might be: personal cloud, hybrid cloud, network cloud, and public cloud [36, 37]. Security issues turn out to be essential at some point of the transport of the offerings and affect person's reputation and use of such offerings [38]. 


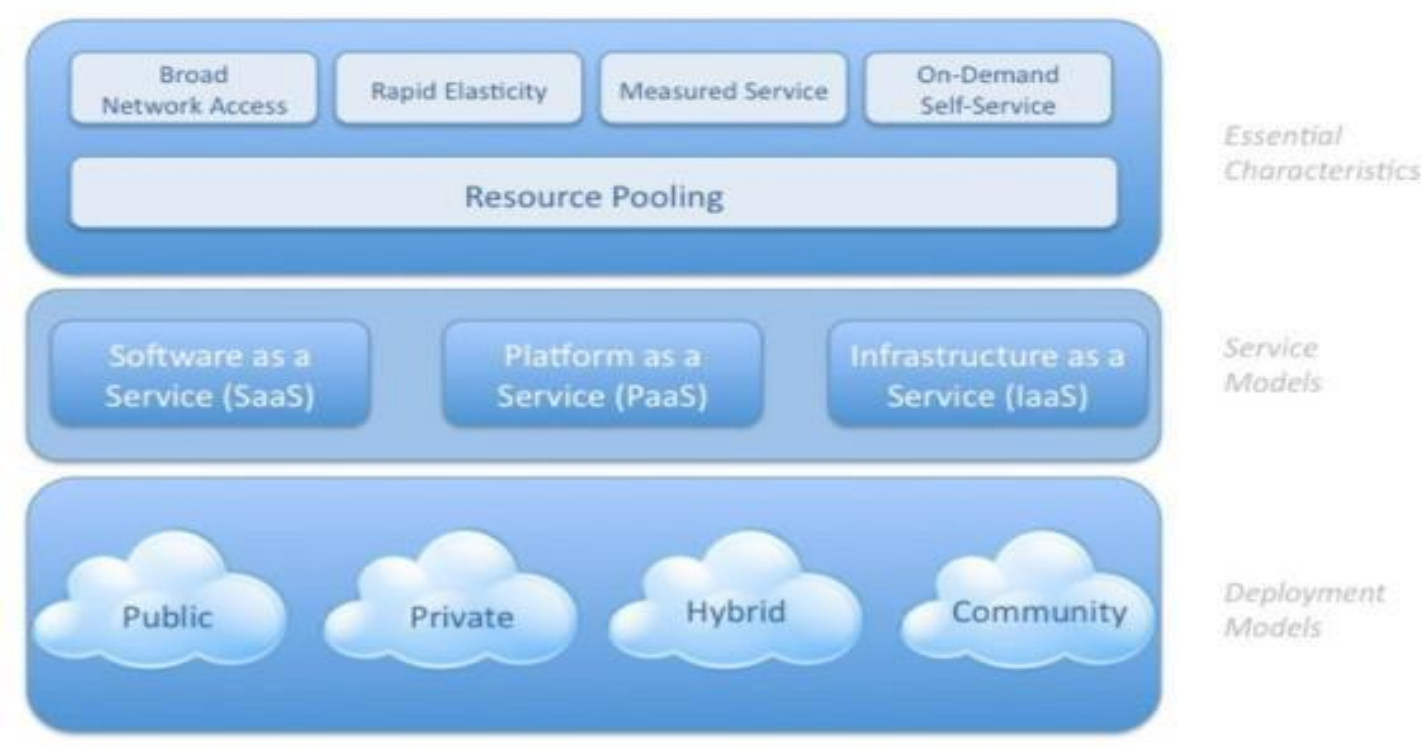

Figure 1 NIST definition of Cloud Computing [36]

\subsection{Cloud Computing with inside the E-authorities Context}

Evidence from preceding studies indicates that cloud generation become followed as a singular channel for the transport of public offerings [39], wherein full-size upgrades with inside the authorities region overall performance, additionally growing progressive public offerings had been detected throughout numerous contexts, international [40]. Around the globe, governments have started to supply numerous offerings primarily based totally at the cloud systems to decorate the offerings quality, recognize performance, lessen fee [41, 42]. Harnessing Cloud Computing (CC) to supply authorities offerings affords some of advantages (e.g. dynamic scalability, accountability, dispensed garage, protection control, and inexperienced IT) [43, 44]. However, there may be a excessive deal of risk, each tangible risk (e.g. availability and infrastructure) and intangible risk (e.g. protection) are related to cloudprimarily based totally e-authorities offerings in conjunction with advantages of the cloud programs [7]. Security issues and applicable troubles are the primary reassets of the risk [45]. Therefore, its required to deal with and perceive such issues for cloud-primarily based totally e-authorities offerings in conjunction with different sorts of dangers. Consequently, governments may have the capacity to risk-control of the cloud systems, that's taken into consideration as the primary determinant of $\mathrm{CC}$ achievement and reputation.

\section{ACCEPTANCE AND ADOPTION OF NEW TECHNOLOGY}

Theories and Models Understanding character-stage of IT reputation is one of the well-installed streams with inside the place of facts machine (IS) studies [46, 47]. Thus a long way exceptional competing fashions and theories had been advanced to apprehend the customers' reputation behaviour of IT/IS. Among those fashions and theories, the TAM, the TPB, the Theory of Reasoned Action (TRA) and so on [48]. There become a want to create a complete version that offers a extra entire photograph of the person's IT reputation manner than any preceding theoretical fashions were capable of do. Venkatesh et al. (2003) advanced the UTAUT version on the idea of integration of 8 dominant theoretical fashions with inside the place of generation reputation (Fig 2) [48]. The UTAUT version consists of 4 middle antecedents (i.e. overall performance expectancy, attempt expectancy, social affect, and facilitating conditions) of behavioural goal and real use behaviour. While gender, revel in, age, and voluntariness had been built because the 4 moderators to the primary relationships (Fig three) [48]. 


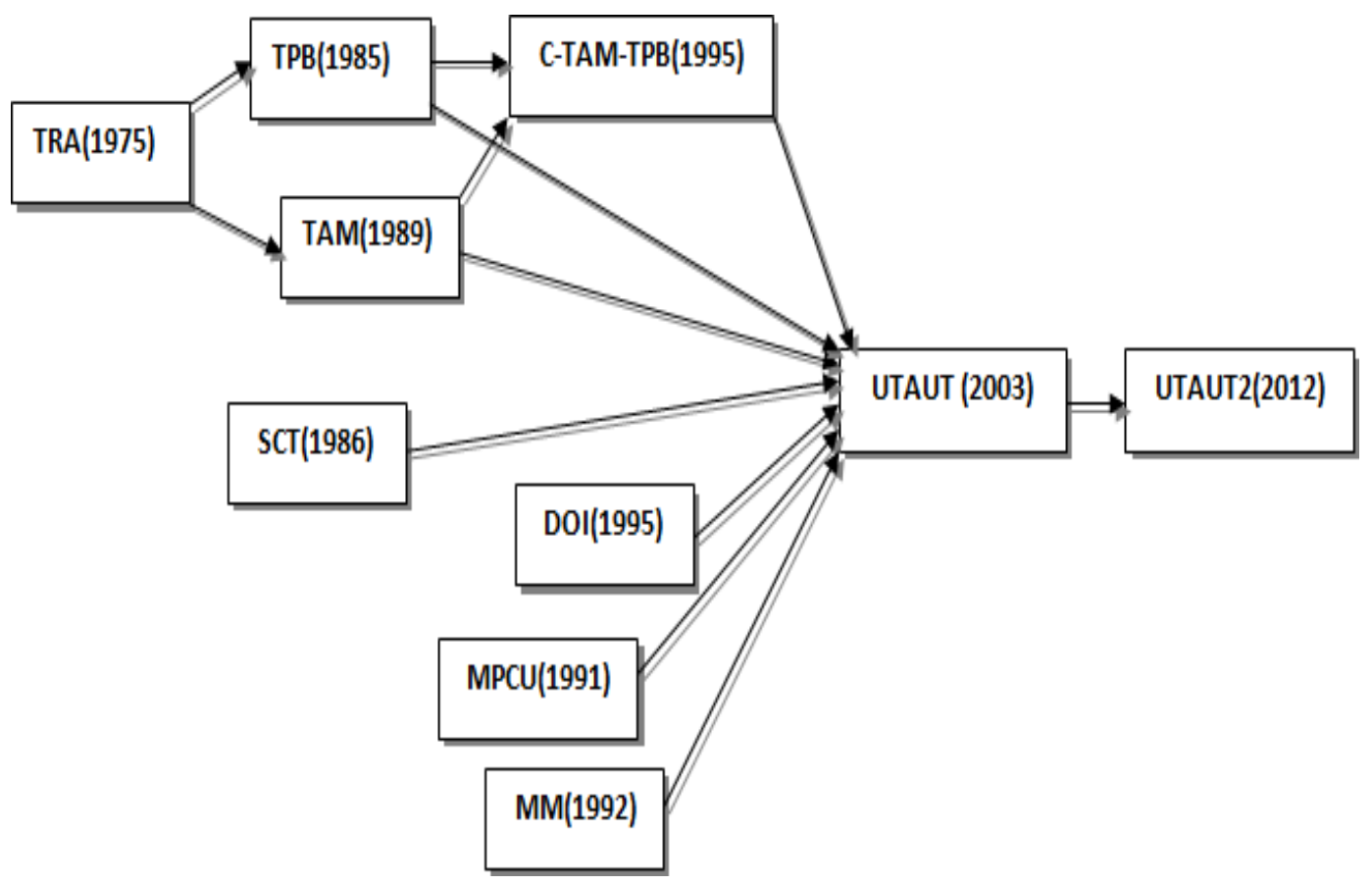

Figure 2 Development of Unified Theory of Acceptance and Use of Technology Model .

Since its inception, the relationships of the UTAUT version had been considerably investigated and showed with inside the context of e-authorities offerings [5, 12, 49]. Thus, the UTAUT is appropriate to apprehend the reputation behaviour of the cloud offerings with inside the e-authorities context. Venkatesh et al. (2012) proposed the UTAUT2 version as an extension to UTAUT version with inside the context client of generation reputation and use [50]. Since residents are the primary customers of e-authorities cloud- primarily based totally offerings, the UTAUT2 can serve the targets of this observe appropriately [51]. Furthermore, in comparison to the unique theoretical fashions, UTAUT2 it could account for a excessive percent with recognize to defined variance (R2) as much as $74 \%$ in behavioural goal (BI) to apply IT, that's extra powerful than any acknowledged character version from the beyond. However, the unified concept (UTAUT/UTAUT2) have a tendency to be criticized because it does now no longer think about the accept as true with and protection issues which constitute of the particular constructs applicable to e-authorities context [4].
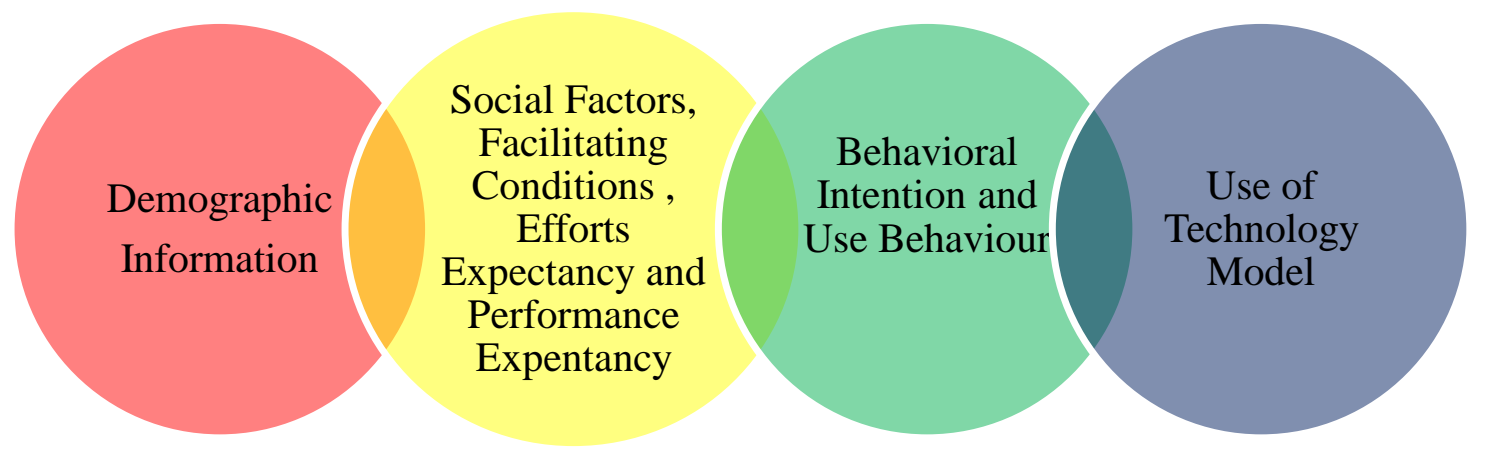

Figure 3 UTAUT [48] 


\section{RESEARCH METHODOLOGY}

In this observe, quantitative studies method using on line questionnaire survey become undertaken to gather the number one statistics and to satisfy the targets of the studies. A survey questionnaire become decided on as it's miles much less time-consuming, inexpensive, the anonymity of respondents may be assured, and it has the capacity to offer a statistics influx from a huge pattern with a minimal stage of researcher bias [52]. A pre-take a look at become carried out after the questionnaire first of all designed with the aid of using a number of the Indian public, $\mathrm{PhD}$ researchers, and educational workforce. This is essential to decorate the questions and test the comprehension of contributors earlier than the real survey is dispensed [53]. This ended in a few adjustments to the wording of few inquiries to make it as express as possible. The questionnaire become applied to decide the energy of Indian residents' perceptions of demanding situations going through the reputation of cloud-primarily based totally e-authorities offerings and the affect of those demanding situations at the perceived protection. In addition, the identical demanding situations had been tested from the angle of offerings providers. IT-workforce on this observe representing a full-size pillar of the general public region so it's miles important to discover the perspectives of IT-professionals concerning this issue. As cloud computing $\mathrm{CC}$ is an nearly new idea with inside the growing nations, the researchers supplied a definition of this progressive IT on the primary web page of the net survey. The on line questionnaire hyperlink become marketed to the focused pattern of the observe the use of exceptional verbal exchange channels (e.g. social media companies, private emails and universities mailing lists). In preferred, the studies pattern may be categorized as Indian residents who're net customers and feature a essential expertise of e- authorities offerings and CC. The 2nd pattern of IT-personnel along with net designers, software program/machine engineers, and programmers, respondents had been approached for responding thru their private contacts ( i.e. emails) in the event that they had private revel in of the e-authorities offerings. The survey includes 4 sections. These are: (1) the respondents' preferred facts (demographic); (2) the respondents' perceptions concerning boundaries and demanding situations going through reputation of cloud-primarily based totally authorities offerings; (three) the respondents' perceptions concerning the safety of cloud-primarily based totally public offerings; (four) the respondents' revel in e- authorities and net use. The survey become carried out primarily based totally at the University of Bradford human studies ethics.

\section{DATA ANALYSIS AND FINDINGS}

The subsequent sections spotlight the important thing findings and gift indicators to the solution of the studies query drawing at the survey findings. An assessment of the net survey questionnaire become supplied with inside the first phase. Then, an example of the consequences of the observe query with extra info become supplied with inside the following 3 sections.

\section{OVERVIEW OF THE ONLINE SURVEY QUESTIONNAIRE}

As delineated above, the net questionnaire is includes 4 components which become supplied in Arabic for less difficult and higher expertise of its questions as Arabic is the local spoken language for residents in India However, the English survey questionnaire become additionally constructed for the motive of the studies. The participation with inside the questionnaire become absolutely voluntarily and knowledgeable consent become secured thru the primary query on the quilt facts sheet indicating that consent is express with the aid of using the "yes" solution to the query. The survey questionnaire become to be had to be accessed thru the net surveys' internet site eSurveyCreator.com. It become open "on line" for one month to all Indians' human beings across the world. By the give up of that time, 243 responses had been received. The 
pattern of this observe includes classes IT workforce and Indian residents. fifty six contributors had been personnel from exceptional authorities businesses in India whilst 187 had been regular Indian residents. However, 23 residents' responses had been discarded due to wrong or lacking solutions. In consequent, a complete of 220 responses had been legitimate for the manner of statistics evaluation, for figuring out the volume wherein the e-authorities demanding situations affect the reputation of cloud offerings with inside the public region from Indian's human beings angle and its effect at the perceived protection. People who understood the cloud offerings (e.g. IT-workforce with inside the public region, ICT region personnel, college students) taken into consideration as a certified pattern. The motive at the back of this feature is that they may be some of the adult's populace whom using net turn out to be a critical a part of their each day existence and has the critical information approximately Cloud Computing offerings. In addition to IT-workforce revel in growing and imparting such offerings. Moreover, because the improvement of Cloud-primarily based totally offerings in India is with inside the preliminary stage, the respondents might be the primary cap potential adopters. Thus, understanding their perceptions and attitudes is essential to enhancing the cloud-primarily based totally eauthorities offerings. The evaluation consequences are certain beneathneath.

\section{INFORMATION (DEMOGRAPHIC)}

The demographic profile of the of the 2 awesome samples (i.e. Indian residents' and ITworkforce) is summarized in Table 2 and Table three. In this survey, best decided on profiles which might be gender, age, training stage, residency, net information stage, protection focus stage had been indexed with the aid of using the authors. Data supplied proof that approximately thirds $(66 \%)$ of respondents had been male and one third (34\%) female. The bias closer to male is attributable to that India is one of the growing nations that touted as a male-ruled society wherein the bulk of female's existence is on the authority and mercy their male's relatives; this may affect exceptional factors along with undertaking authorities transactions and employment with inside the public region. In phrases of age, the findings found out that the biggest percent of the overall populace pattern had been elderly especially among (21-forty) years old, steady with the biggest majority of Indian net customers. Most of the respondents preserve a bachelor diploma as training qualification stage which is available in settlement with the overall distribution of net customers in India seventy eight\% of residents' respondents are from India or different growing nations, whilst $22 \%$ are from growing nations just like the United Kingdom and the USA. In preferred, the residents' respondents had been self-diagnosed as having medium net information and amateur to medium protection focus. By evaluation, the primary distinction with inside the IT-workforce pattern become self-identity as having a pretty superior net information and protection focus.

Table 2 General Information (Demographic) for IT-Staff in Public region

\begin{tabular}{|l|l|}
\hline Attributes & Percentage(\%) \\
\hline Gender & \\
\hline M & $69 \%$ \\
\hline F & $31 \%$ \\
\hline Age & \\
\hline $20-30$ & $41 \%$ \\
\hline $30-40$ & $54 \%$ \\
\hline $40-50$ & $5 \%$ \\
\hline Education Qualification & \\
\hline Diploma & $25 \%$ \\
\hline Bachelor & $66 \%$ \\
\hline Postgraduate & $9 \%$ \\
\hline
\end{tabular}




\begin{tabular}{|l|l|}
\hline Nationality Country & \\
\hline $\begin{array}{l}\text { India or developing } \\
\text { countries }\end{array}$ & $100 \%$ \\
\hline Internet Knowledge & \\
\hline Advanced & $100 \%$ \\
\hline Security Awareness & \\
\hline Medium & $73 \%$ \\
\hline Advanced & $27 \%$ \\
\hline
\end{tabular}

Table 3 General Information (Demographic) for Indian Citizens

\begin{tabular}{|l|l|}
\hline Attributes & Percentage(\%) \\
\hline Gender & \\
\hline M & $66 \%$ \\
\hline F & $34 \%$ \\
\hline Age & \\
\hline $18-20$ & $3 \%$ \\
\hline $21-30$ & $68 \%$ \\
\hline $31-40$ & $16 \%$ \\
\hline $41-50$ & $11 \%$ \\
\hline $50+$ & $2 \%$ \\
\hline Qualification Level & \\
\hline Secondary School orbelow & $7 \%$ \\
\hline Diploma & $8 \%$ \\
\hline Bachelor & $63 \%$ \\
\hline Postgraduate & $22 \%$ \\
\hline Nationality Country & \\
\hline $\begin{array}{l}\text { India or developing } \\
\text { countries }\end{array}$ & $78 \%$ \\
\hline Developed countries & $22 \%$ \\
\hline Internet Knowledge Level & \\
\hline Beginner & $2 \%$ \\
\hline Medium & $60 \%$ \\
\hline Advanced & $38 \%$ \\
\hline Security Awareness Level & $57 \%$ \\
\hline Beginner & $32 \%$ \\
\hline Medium & $11 \%$ \\
\hline Advanced & \\
\hline
\end{tabular}

This assessment of the overall demographic profile of the contributors will assist with inside the consequences' interpretation and offer the solution to the studies query with inside the subsequent sections.

\section{CHALLENGES TO CLOUD-BASED E- GOVERNMENT SERVICES ACCEPTANCE}

Interpretation of the observe Question According to the consequences, there are some of demanding situations and boundaries of e-authorities reputation and adoption, which might be: technological, human- factors, social, and economic which are nevertheless impede the reputation and use of cloud computing offerings in Indian public region from the contributors' angle ( Fig four). A quantity of authors indicated that the diffusion of progressive technologies (e.g. e- authorities offerings) into residents and societies isn't with out demanding situations. However, the authorities region faces boundaries from residents who assume better requirements of the general public offerings (i.e. governmental) than from offerings of the 
personal region. Nine boundaries had been diagnosed to reputation of e-authorities offerings with the aid of using the researchers primarily based totally on literature evaluate. In consequent, respondents had been requested for comparing their notion of the significance stage for every barrier with the aid of using thinking about the demanding situations if it does now no longer constitute one (zero), essential one (1), or very essential one (2).

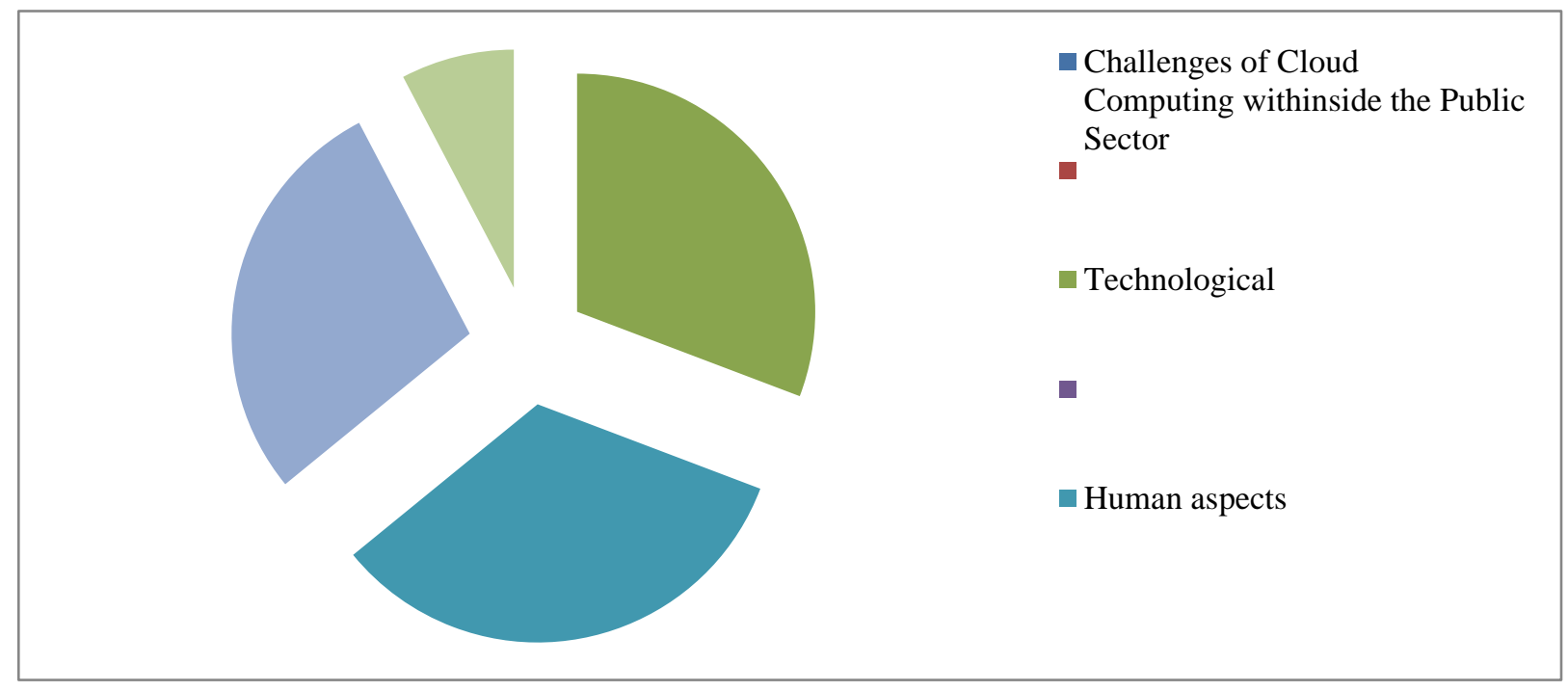

Figure 4 Challenges of Cloud Computing with inside the Public Sector

\subsection{Citizens' Perceptions Regarding Barriers of Cloud-Based E-Government offerings}

Tables four, five indicates all of the 9 boundaries had been selected as both very essential or essential barrier and no one of the 9 become selected as now no longer a project from all contributors.

Table 4 Very Important Barriers to Accept Cloud- Based Services from Citizens' Perspectives

\begin{tabular}{|l|l|l|}
\hline S. No & Obstruction & $\begin{array}{l}\text { Major obstructions } \\
\text { Percent \% }\end{array}$ \\
\hline 1 & IT infrastructure & $50 \%$ \\
\hline 2 & Security & $80 \%$ \\
\hline 3 & Availability & $30 \%$ \\
\hline 4 & Accessibility & $40 \%$ \\
\hline 5 & Website design & $42 \%$ \\
\hline 6 & Lack of awareness & $80 \%$ \\
\hline 7 & IT skills & $30 \%$ \\
\hline 8 & Culture & $70 \%$ \\
\hline 9 & $\begin{array}{l}\text { Lack of budget / } \\
\text { high cost }\end{array}$ & $20 \%$ \\
\hline
\end{tabular}


Table 5 Important Barriers to Accept Cloud-Based Services from Citizens' Perspectives

\begin{tabular}{|l|l|l|}
\hline S.No & Obstructions & $\begin{array}{l}\text { Important } \\
\text { obstructions }\end{array}$ \\
\hline & & Percent \% \\
\hline 1 & IT infrastructure & $50 \%$ \\
\hline 2 & Security & $15 \%$ \\
\hline 3 & Availability & $65 \%$ \\
\hline 4 & Accessibility & $60 \%$ \\
\hline 5 & Website design & $49 \%$ \\
\hline 6 & Lack of awareness & $15 \%$ \\
\hline 7 & IT skills & $60 \%$ \\
\hline 8 & Culture & $30 \%$ \\
\hline 9 & $\begin{array}{l}\text { Lack of budget /high } \\
\text { cost }\end{array}$ & $65 \%$ \\
\hline
\end{tabular}

\subsection{IT-Employees' Perceptions Regarding Barriers of Cloud-Based E- Government offerings}

The evaluation of the IT-personnel' perspective approximately the boundaries at the 2 perceptions degrees is summarized in Tables 6,7. Again, Lack of focus and protection are the 2 maximum famous demanding situations as illustrated with inside the subsequent subsection.

Table 6 Very Important Barriers to Accept Cloud-Based Services from IT-Staff Perspectives

\begin{tabular}{|l|l|l|}
\hline S.No & Obstacle & Important obstacle \\
\hline & & Percent \% \\
\hline 1 & IT infrastructure & $15 \%$ \\
\hline 2 & Security & $20 \%$ \\
\hline 3 & Availability & $40 \%$ \\
\hline 4 & Accessibility & $35 \%$ \\
\hline 5 & Website design & $30 \%$ \\
\hline 6 & Lack of awareness & $7 \%$ \\
\hline 7 & IT skills & $60 \%$ \\
\hline 8 & Culture & $30 \%$ \\
\hline 9 & Lack of budget /high cost & $60 \%$ \\
\hline
\end{tabular}

\subsection{Respondents' Perceptions Regarding the "Very Important" obstacle}

Inspecting the very best boundaries that residents and IT personnel perceived as being "very essential" it could be observed that the lack of expertise approximately the cloud-primarily based totally offerings and its advantages with inside the e-authorities context become famous at (87.eight\%) and (94.6\%), respectively. This suggests that promotional applications are probable to be an essential aspect for the achievement of e-authorities projects [54]. For any modern generation (e.g. cloud offerings for the general public region) there some of steps that might assist in convincing and inspiring human beings to just accept it first then use it. Research 
into adoption and use of cloud-primarily based totally offerings indicates that potential customers required to understand that it is simple and handy to apply, useful, and it provide a relative benefit in comparison to the modern-day approaches of appearing the things (shin 2013). For residents and different stakeholders to increase such perceptions earlier than acquiring good sized revel in, promotional sports and marketing and marketing will make contributions extensively to perform this intention. Security issues of facts and offerings supplied with the aid of using e-authorities structures come as a 2nd "very essential" barrier with a recognition of $(86.6 \%)$ and $(82.1 \%)$. There is a consensus amongst researchers that it's miles a severe technical barrier and it's also a well-documented angle for the implementation of e-authorities offerings international $[14,26,55]$.

\subsection{Comparison of Barriers Perceptions}

This phase targets to examine the primary standpoints of Indian residents and IT-personnel concerning the boundaries to just accept and use of cloud- primarily based totally e-authorities offerings. It is obvious from the preceding sub-sections that there are some of perceived demanding situations which are not unusual place among each. Firstly, for each of pattern classes, the lack of expertise approximately the cloud-primarily based totally public offerings and its advantages as "very essential" project and ranked it because the maximum full-size one with inside the listing. This consensus among each pattern classes suggests that it's miles a important impediment to be resolved, thinking of a excessive-stage of precedence. Next, each of pattern populations agreed that Security of public offerings become diagnosed as the second one essential barrier with inside the listing of "very essential". At last, there has been a distinction with inside the subsequent maximum full-size "very essential" project to the cloudprimarily based totally e-authorities reputation, this displays the people' angle of pattern classes. For the IT-workforce in the authorities businesses, the weak spot of the IT infrastructure become considered as the subsequent ranked barrier as that allow them to offer powerful public offerings. With recognize to the regular residents' views, society tradition affects the a success use of progressive authorities offerings. Table: 8 provides a précis of the not unusual place and awesome boundaries with their rank in step with their recognition.

Table 8 Common and Different obstacles between the Sample Categories

\begin{tabular}{|l|l|l|l|}
\hline S.No & Obstacles & Percentage \\
\hline & & $\begin{array}{l}\text { IT- } \\
\text { workers }\end{array}$ & Citizens \\
\hline $\mathbf{1}$ & Lack of awareness & $90 \%$ & $84 \%$ \\
\hline $\mathbf{2}$ & Security & $76 \%$ & $80 \%$ \\
\hline $\mathbf{3}$ & IT infrastructure & $75 \%$ & $46 \%$ \\
\hline $\mathbf{4}$ & Culture & $70 \%$ & $65 \%$ \\
\hline
\end{tabular}

\subsection{Security Perceptions of Cloud-Based E- Government Services}

Seven of the e-authorities boundaries with inside the survey have an effect on the safety perceptions of the respondents (i.e. residents and IT personnel) closer to the reputation and use of cloud offerings. It is apparent from Table nine that there may be settlement at the rating of those boundaries from the viewpoints of the pattern each side. These had been ranked primarily based totally at the responses percent which both suggests strongly agree or agree. 
Table 9 Perceived Security Barriers to Accept Cloud-Based Services in the E-Government

\begin{tabular}{|c|c|c|c|}
\hline \multirow[t]{2}{*}{ Rank } & \multirow[t]{2}{*}{ Obstacles } & \multicolumn{2}{|c|}{ Agreement } \\
\hline & & Citizens & $\begin{array}{l}\text { IT } \\
\text { employees }\end{array}$ \\
\hline 1 & $\begin{array}{l}\text { High level of security concerns } \\
\text { regarding "cloud-based e-government" } \\
\text { services are inspired by non-technical } \\
\text { aspects (e.g. } \\
\text { culture and awareness) }\end{array}$ & $75 \%$ & $85 \%$ \\
\hline 2 & $\begin{array}{l}\text { Social relations and culture have a } \\
\text { significant influence on the security of } \\
\text { "cloud- based e-government" } \\
\text { services }\end{array}$ & $70 \%$ & $80 \%$ \\
\hline 3 & $\begin{array}{l}\text { Lack of security awarenessis one of } \\
\text { the main determinants of the user's } \\
\text { perception regarding the } \\
\text { security of "cloud-based e- } \\
\text { government" services. }\end{array}$ & $65 \%$ & $78 \%$ \\
\hline 4 & $\begin{array}{l}\text { Perceived security is a significant } \\
\text { resource for public users' trust of } \\
\text { "cloud-based } \quad \text { e-government" } \\
\text { services. }\end{array}$ & $60 \%$ & $75 \%$ \\
\hline 5 & $\begin{array}{l}\text { The design of the "cloud- based e- } \\
\text { government" website influence the } \\
\text { user } \\
\text { perception of its security }\end{array}$ & $55 \%$ & $60 \%$ \\
\hline 6 & $\begin{array}{l}\text { There is a lack of security guidelines } \\
\text { for using "cloud-based e-government" } \\
\text { services, on the government website, } \\
\text { social media or other media channels. }\end{array}$ & $50 \%$ & $60 \%$ \\
\hline 7 & $\begin{array}{l}\text { There is a lack ofregulations and } \\
\text { policies to use cloud public services. }\end{array}$ & $40 \%$ & $53 \%$ \\
\hline
\end{tabular}

For the boundaries that the 2 observe samples perceived as a protection project related to reputation and adoption of cloud-primarily based totally e- authorities, it's miles clean that the non-technical factors along with tradition and focus were given the very best rank at $(83.6 \%)$ and $(90.3 \%$ ) respectively (Fig five, 6 ). Thus, the primary interest ought to be paid to this regions with the aid of using the offerings issuer(i.e. authorities). 


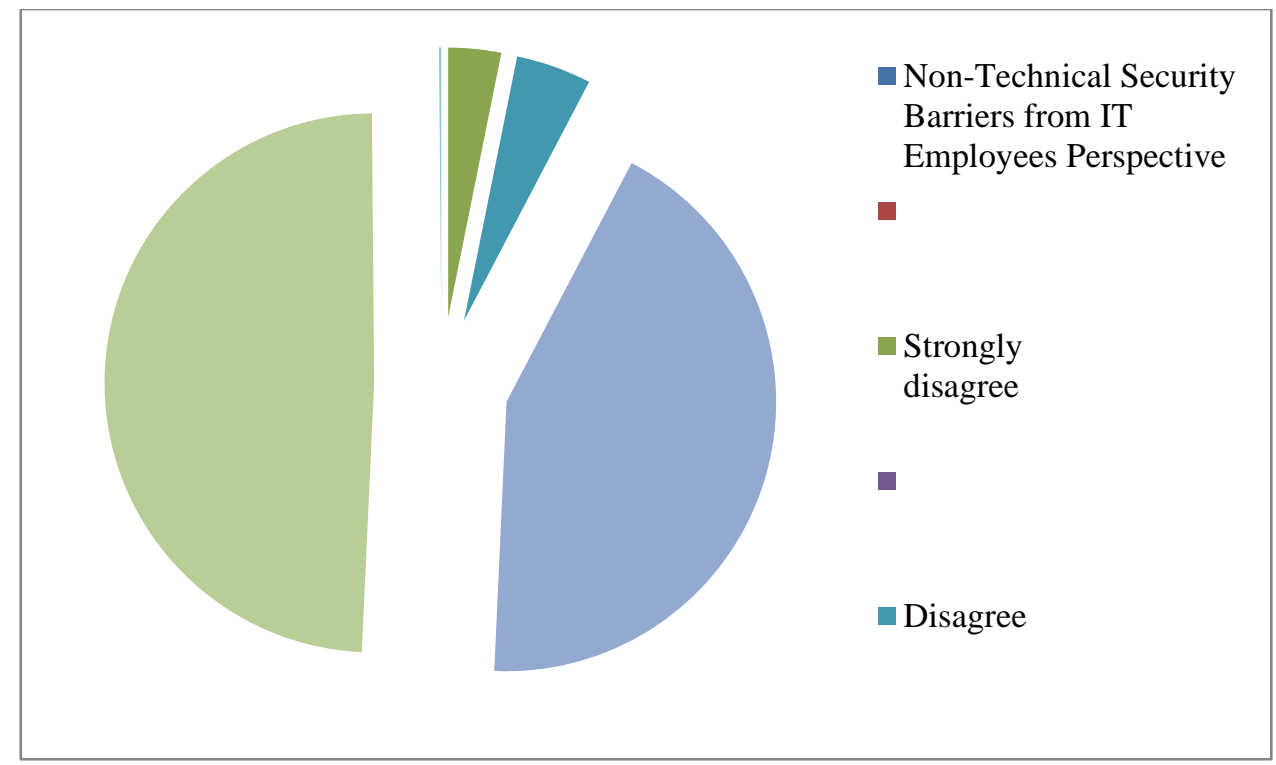

Figure 5 Non-Technical Security Barriers from Citizens Perspective

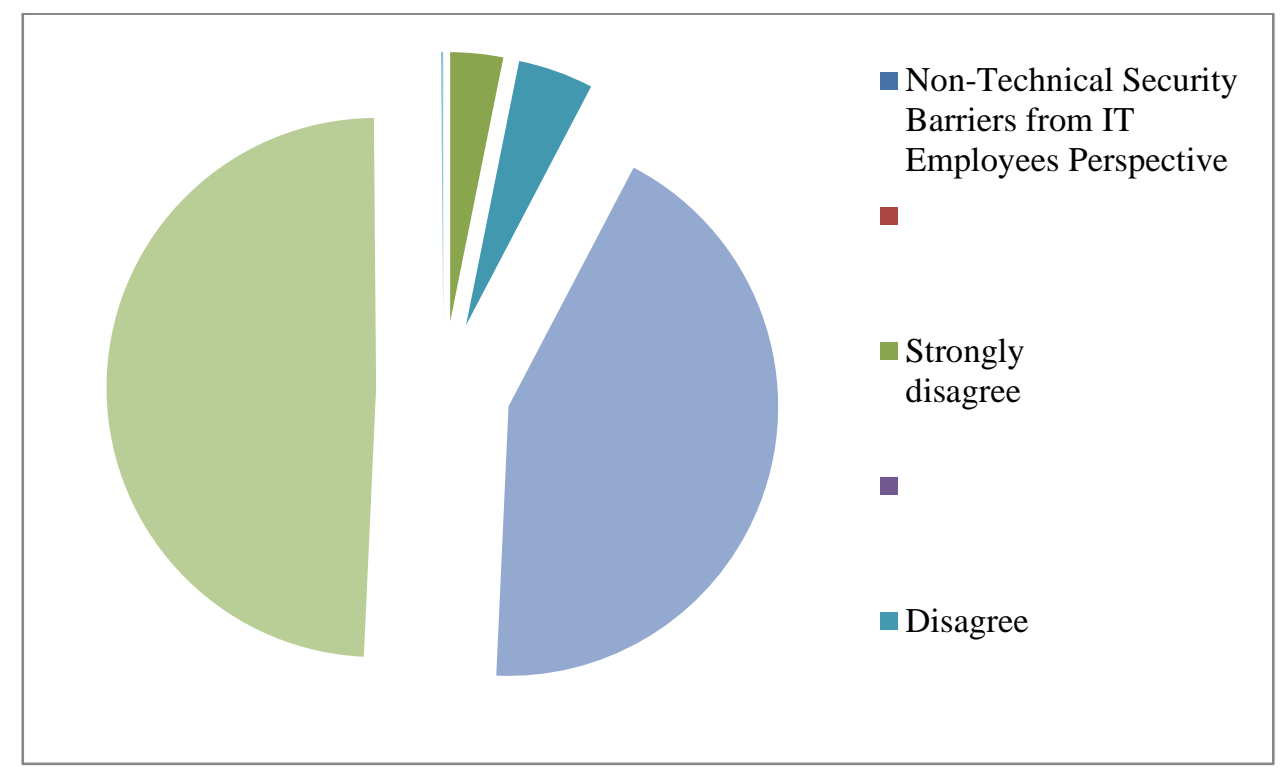

Figure 6 Non-Technical Security Barriers from IT Employees Perspective

The implementation of progressive e-authorities offerings faces the project of cultural inertia which required to be overcome, specifically in growing nations [35]. The cultural troubles have a exceptional affect among advanced and growing nations. To supply an example, the survey findings found out that extra than $(64 \%)$ of the residents' pattern who stay in advanced nations choose to behavior on line transactions in comparison to approximately (35\%) of these in India and different growing nations (Fig 7). The solutions indicated that the primary motive is cultural differences, one of the respondents who stay in India said: " I heard approximately many those who their cash become stolen while they are trying to shop for on line" whilst a 2nd commented: " digital transactions isn't assured I choose to touch the alternative men and women head to head and feature a risk of dialogue". Furthermore, tradition continues to be deemed to be as one of the boundaries in handling the perceived protection of cloud-primarily based totally e-authorities offerings $(81.1 \%)$ and $(89.2 \%)$ respectively. Accordingly, it's miles vital to teach and educate regular residents to construct an progressed 
tradition concerning the advantages, significance, protection of on line transactions, specifically cloud offerings for authorities region the use of some of promotional approaches.

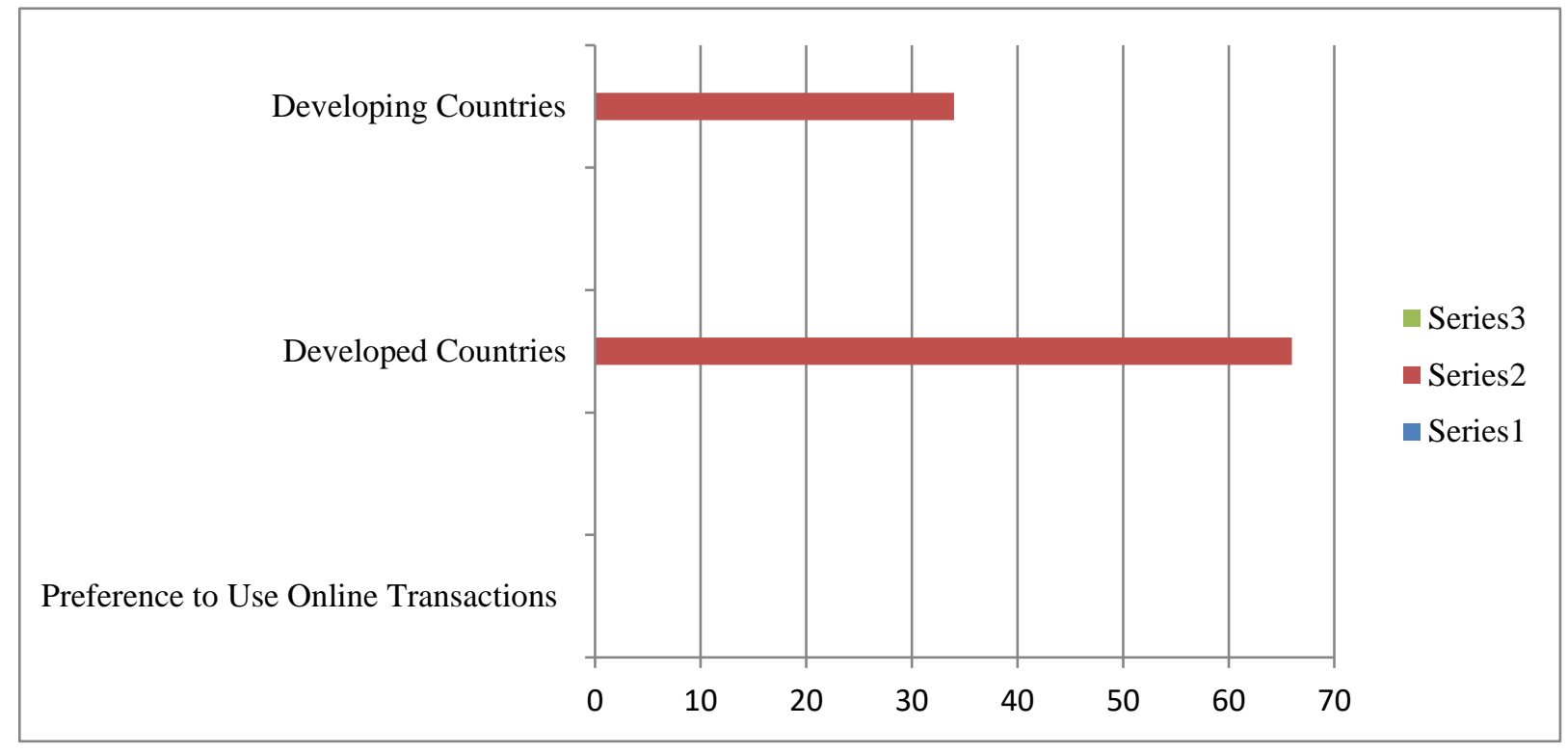

Figure 7 Preference to Use Online Transactions

\section{CONCLUSION AND FUTURE WORK}

E-authorities structures primarily based totally on cloud generation are the modern-day path in on line offerings and facts around the world. Government businesses, specifically the ones in growing nations who aspire to decorate e- authorities, can seek advice from those observe findings to sell and layout their offerings. For instance, they are able to layout numerous promotional programmes and sports for numerous customers. It is usually recommended to make investments cash in a vast and appealing focus marketing campaign to inspire residents efficiently to just accept and use cloud offerings. Additionally, those who use cloud- offerings to behavior governmental transactions might have a reduction in phrases of the transactions fees. This will assist to elevate the utilization charges, especially for people who nevertheless refuse using the e-authorities offerings, in preferred, attributable to some of issues along with protection and accept as true with. The predominant intention of this paper is to consciousness at the e-authorities demanding situations and the way it affects the reputation of the cloudprimarily based totally offerings in the public region context and to what volume those demanding situations have an effect on the perceived protection. The findings of this studies attempt had been primarily based totally at the responses IT workforce with inside the public region and Indian residents to the studies query. This become carried out for helping the manner of decision- making with the aid of using the stakeholders of e-authorities, and to enhance the effects of the cloud-primarily based totally e- authorities offerings supplied for the Indian society. The demanding situations had been diagnosed primarily based totally on a applicable literature evaluate and tested thru wearing out a survey. The findings of the survey showed that protection issues play a full-size position with inside the reputation and use of cloud offerings with inside the authorities context (2nd rank). In addition, it found out that the non-technical factors have a amazing significance some of the different protection troubles with inside the observe context. In consequent, thinking about those demanding situations and incorporating them with IT/IS reputation version is wanted for destiny studies paintings. Owing to its excessive explanatory electricity evaluating to the preceding theories and fashions of generation reputation and additionally its suitability to e-authorities cloud-primarily based totally 
offerings, the UTAUT2 version might be advanced choice imparting the bottom for the destiny proposed theoretical version addressing the reputation of such offerings.

\section{REFERENCES}

[1] E. Abu-Shanab, "Antecedents of trust in e- government services: an empirical test in India," Transforming Government: People, Process and Policy, vol. 8, no. 4, pp. 480-499, 2014.

[2] A. T. Al-Zyadat, "e government systems and its impact on quality of service at public hospitals in amman (filed study)," InternationalJournal of Management (IJM), vol. Volume 7, Issue 6, September-October 2016, pp.01-05, 2016.

[3] O. Al-Hujran, M. M. Al-Debei, A. Chatfield, and M. Migdadi, "The imperative of influencing citizen attitude toward e-government adoption and use," Computers in human Behavior, vol. 53, pp. 189-203, 2015.

[4] Y. K. Dwivedi, N. P. Rana, M. Janssen, B. Lal, M. D. Williams, and M. Clement, "An empirical validation of a unified model of electronic government adoption (UMEGA)," Government Information Quarterly, 2017.

[5] Y.-S. Wang and Y.-W. Shih, "Why do people use information kiosks? A validation of the Unified Theory of Acceptance and Use of Technology," Government InformationQuarterly, vol. 26, no. 1, pp. 158-165, 2009.

[6] Y. K. Dwivedi and N. Mustafee, "It's unwritten in the Cloud: the technology enablers for realising the promise of Cloud Computing," Journal of Enterprise Information Management, vol. 23, no. 6, pp. 673-679, 2010.

[7] S. Paquette, P. T. Jaeger, and S. C. Wilson, "Identifying the security risks associated with governmental use of cloud computing," Government Information Quarterly, vol. 27, no. 3, pp. 245-253, 2010.

[8] T. Almarabeh, Y. K. Majdalawi, and H. Mohammad, "Cloud Computing of E- Government," ed: Communications andNetwork, 2016, 8, 1- 8, 2016.

[9] D. C. Wyld, "The cloudy future of government IT: Cloud computing and the public sector around the world," International Journal of Web \& Semantic Technology, vol. 1, no. 1, pp. 1$20,2010$.

[10] N. N. Almutairi and S. F. Thuwaini, "Cloud Computing Uses for E-Government in the Middle East Region Opportunities and Challenges," International Journal of Business and Management, vol. 10, no. 4, p. 60, 2015.

[11] Microsoft. (2014, 30/6/2017). Microsoft inGovernment : Customer Stories(The Hashemite Kingdom of India)August 15, 2014. Available: https://enterprise.microsoft.com/enus/customer- story/industries/government/the-hashemite- kingdom-of-India/

[12] V. Weerakkody, R. El-Haddadeh, F. Al-Sobhi, M. A. Shareef, and Y. K. Dwivedi, "Examining the influence of intermediaries in facilitating e- government adoption: An empirical investigation," International Journal of Information Management, vol. 33, no. 5, pp. 716-725, 2013/10/01/ 2013.

[13] H. Al-Rashidi, "The role of internal stakeholders and influencing factors during the phases of egovernment initiative implementation," 2013. 
[14] D. Belanche-Gracia, L. V. Casalo-Arino, and A. Pérez-Rueda, "Determinants of multi-service smartcard success for smart cities development: A study based on citizens' privacy and security perceptions," Government information quarterly, vol. 32, no. 2, pp. 154-163, 2015.

[15] A. Savoldelli, C. Codagnone, and G. Misuraca, "Understanding the e-government paradox: Learning from literature and practice on barriers to adoption," Government Information Quarterly, vol. 31, pp. S63-S71, 2014.

[16] Z. Ebrahim and Z. Irani, "E-government adoption: architecture and barriers," Business process management journal, vol. 11, no. 5, pp. 589-611, 2005.

[17] T. Almarabeh and A. AbuAli, "A general framework for e-government: definition maturity challenges, opportunities, and success,"European Journal of Scientific Research, vol. 39, no. 1, pp. 29-42, 2010.

[18] V. Ndou, "E-government for developing countries: opportunities and challenges," The electronic journal of information systems in developing countries, vol. 18, 2004.

[19] H. R. Nemati, Information Security and Ethics: Concepts, Methodologies, Tools, and Applications (no. Book, Whole). US: Information Science Reference (Isr), 2008.

[20] R. K. Chellappa and P. A. Pavlou, "Perceived information security, financial liability and consumer trust in electronic commerce transactions," Logistics Information Management, vol. 15, no. 5/6, pp. 358-368, 2002.

[21] S. Alateyah, R. M. Crowder, and G. B. Wills, "Citizen adoption of E-government services," in International Conference on Information Society (i-Society 2012), 2012, pp. 182-187: IEEE.

[22] M. Alomari, P. Woods, and K. Sandhu, "Predictors for e-government adoption in India: Deployment of an empirical evaluation based on a citizen-centric approach," Information Technology \& People, vol. 25, no. 2, pp. 207- 234, 2012.

[23] J. I. Criado and M. C. Ramilo, "E-government in practice: an analysis of Web site orientation tothe citizens in Spanish municipalities," (in English), International Journal of Public Sector Management, vol. 16, no. 3, pp. 191-218, 00, 2003.2016-09-27 2003.

[24] M. Rehman and V. Esichaikul, "Factorsinfluencing the adoption of e-government in Pakistan," in E -Business and E -Government(ICEE), International Conference, pp. 1-4, 2011, pp. 1-4: IEEE.

[25] S. A. Alateyah, R. M. Crowder, and G. B. Wills, "Identified factors affecting the citizen's intention to adopt e-government in saudi arabia,"2013, p. 904: World Academy of Science, Engineering and Technology (WASET).

[26] S. Sang, J.-D. Lee, and J. Lee, "E-Government challenges in least developed countries (LDCs): a case of Cambodia," 2009, vol. 3, pp. 2169- 2175: IEEE.

[27] A. Dugdale, A. Daly, F. Papandrea, and M. Maley, "Accessing e-government: challenges for citizens and organizations," International Review of Administrative Sciences, vol. 71, no. 1, pp. 109-118, 2005.

[28] V. Weerakkody, R. El-Haddadeh, and S. Al- Shafi, "Exploring the complexities of egovernment implementation and diffusion in a developing country: Some lessons from the State of Qatar," Journal of Enterprise Information Management, vol. 24, no. 2, pp. 172-196, 2011. 
[29] N. P. Rana, Y. K. Dwivedi, and M. D. Williams, "Analysing challenges, barriers and CSF of egov adoption," Transforming Government: People, Process and Policy, vol. 7, no. 2, pp. 177198, 2013.

[30] A. M. Odat, "E-GOVERNMENT IN DEVELOPING COUNTRIES: FRAMEWORK OF CHALLENGES AND OPPORTUNITIES," Journal of Theoretical and Applied Information Technology, vol. Vol. 46 No.2, pp. 1013-1021, 2012.

[31] S. Furnell and L. Moore, "Security literacy: the missing link in today's online society?," Computer Fraud \& Security, vol. 2014, no. 5, pp. 12-18, 5// 2014.

[32] M. E. Alzahrani and R. D. Goodwin, "Towards a UTAUT-based Model for the Study of EGovernment Citizen Acceptance in Saudi Arabia," World Academy of Science,Engineering and Technology, InternationalJournal of Social, Behavioral, Educational, Economic, Business and Industrial Engineering, vol. 6, no. 4, pp. 376-382, 2012.

[33] K. Roer, Build a security culture. IT GovernancePublishing, 2015.

[34] A. Carvin, J. Hill, and S. Smothers, E- government for all: Ensuring equitable access to online government services. The EDC center for media \& community and the NYS Forum, 2004.

[35] M. Ali, V. Weerakkody, and R. El-Haddadeh, "The impact of national culture on e-government implementation: A comparison case study," 2009.

[36] P. Mell and T. Grance, "The NIST definition of cloud computing," 2011.

[37] N. Wang, H. Liang, Y. Jia, S. Ge, Y. Xue, and Z.Wang, "Cloud computing research in the IS discipline: A citation/co-citation analysis," Decision Support Systems, vol. 86, pp. 35-47, 2016.

[38] I. Arpaci, "Understanding and predicting students' intention to use mobile cloud storage services," Computers in Human Behavior, vol. 58, pp. 150-157, 2016.

[39] K. K. Smitha, T. Thomas, and K. Chitharanjan, "Cloud Based E-Governance System: A Survey,"Procedia Engineering, vol. 38, pp. 3816-3823, 2012/01/01/ 2012.

[40] S. Hashemi, K. Monfaredi, and M. Masdari, "Using cloud computing for e-government: challenges and benefits," International Journal of Computer, Information, Systems and Control Engineering, vol. 7, no. 9, pp. 596-603, 2013.

[41] D.-H. Shin, "User centric cloud service model in public sectors: Policy implications of cloud services," Government Information Quarterly, vol. 30, no. 2, pp. 194-203, 4// 2013.

[42] O. Ali, J. Soar, J. Yong, H. McClymont, and D. Angus, "Collaborative cloud computing adoption in Australian regional municipal government: An exploratory study," in 19th International Conference on Computer Supported Cooperative Work in Design (CSCWD), 2015, pp. 540-548: IEEE.

[43] M. A. Aveek and M. Rahman, "Implementing e- governance in Bangladesh using cloud computing technology," 2011.

[44] A. Tripathi and B. Parihar, "E-governance challenges and cloud benefits," in IEEEInternational Conference on Computer Science and Automation Engineering (CSAE), 2011,2011, vol. 1, pp. 351-354: IEEE. 
[45] D. Zissis and D. Lekkas, "Securing e-Government and e-Voting with an open cloud computing architecture," GovernmentInformation Quarterly, vol. 28, no. 2, pp. 239- 251, 2011.

[46] V. Venkatesh, J. Y. L. Thong, and X. Xu, "Unified theory of acceptance and use of technology: a synthesis and the road ahead," 2016.

[47] A. Alkhwaldi and M. Kamala, "Why Do Users Accept Innovative Technologies? A critical review of technology acceptance models and theories," Journal of Multidisciplinary Engineering Science and Technology (JMEST), vol. Vol. 4 Issue 8, August -2017, pp. 79627971, 2017.

[48] V. Venkatesh, M. G. Morris, G. B. Davis, and F.D. Davis, "User acceptance of information technology: Toward a unified view," MIS quarterly, pp. 425-478, 2003.

[49] S. AlAwadhi and A. Morris, "The Use of the UTAUT Model in the Adoption of E- government Services in Kuwait," in Proceedings of the 41st Hawaii International Conference on System Sciences, 2008, pp. 219-219: Ieee.

[50] V. Venkatesh, J. Y. L. Thong, and X. Xu, "Consumer acceptance and use of information technology: extending the unified theory of acceptance and use of technology," 2012.

[51] M. Z. I. Lallmahomed, N. Lallmahomed, and G.M. Lallmahomed, "Factors influencing the adoption of e-Government services in Mauritius," Telematics and Informatics, vol. 34, no. 4, pp. 57-72, 2017.

[52] D. E. Gray, Doing research in the real world, Third ed. (no. Book, Whole). London: SAGE Publications Ltd, 2014.

[53] M. Saunders, P. Lewis, and A. Thornhill, Research methods for business students, Seventh ed. (no. Book, Whole). Harlow, Essex: Pearson Education Limited, 2016.

[54] M. Ovais Ahmad, J. Markkula, and M. Oivo, "Factors affecting e-government adoption in Pakistan: a citizen's perspective," Transforming Government: People, Process and Policy, vol. 7, no. 2, pp. 225-239, 2013.

[55] VNSS Chimakurthi, Application Portfolio Profiling and Appraisal as Part of Enterprise Adoption of Cloud Computing, Global Disclosure of Economics and Business, 2019, Volume 8, No 2, pp. 129-142

[56] J.-W. Lian, "Critical factors for cloud based e- invoice service adoption in Taiwan: An empirical study," International Journal of Information Management, vol. 35, no. 1, pp. 98- 109, 2015. 